NASA Technical Memorandum 105155

AIAA-91-2128

\title{
Comparison of a Quasi-3D Analysis and Experimental Performance for Three Compact Radial Turbines
}

P.S. Simonyi

Sverdrup Technology, Inc.

Lewis Research Center Group

Brook Park, Ohio

and

R.J. Boyle

National Aeronautics and Space Administration

Lewis Research Center

Cleveland, Ohio

Prepared for the

27th Joint Propulsion Conference

cosponsored by the AIAA, SAE, ASME, and ASEE

Sacramento, California, June 24-27, 1991 


\title{
COMPARISON OF A QUASI-3D ANALYSIS AND EXPERIMENTAL PERFORMANCE FOR THREE COMPACT RADIAL TURBINES
}

\author{
P.S. Simonyi \\ Sverdrup Technology, Inc. \\ Lewis Research Center Group \\ Brook Park, Ohio 44142 \\ R.J. Boyle \\ NASA Lewis Research Center \\ Cleveland, Ohio 44135
}

\section{ABSTRACT}

An experimental aerodynamic evaluation of three compact radial turbine builds was performed. Two rotors which were $40-50$ percent shorter in axial length than conventional state-of-the-art radial rotors were tested. A single nozzle design was used. One rotor was tested with the nozzle at two stagger angle settings. A second rotor was tested with the nozzle in only the closed down setting. Experimental results were compared to predicted results from a quasi3D inviscid and boundary layer analysis, called MTSB (Meridl/Tsonic/Blayer). This analysis was used to predict turbine performance. It has previously been calibrated only for axial, not radial, turbomachinery. The predicted and measured efficiencies were compared at the design point for the three turbines. At the design points the analysis overpredicted the efficiency by less than 1.7 points. Comparisons were also made at offdesign operating points. The results of these comparisons showed the importance of an accurate clearance model for efficiency predictions and also that there are deficiencies in the incidence loss model used.

\section{INTRODUCTION}

Radial turbines have the advantage over axial turbines in their ability to extract high work per stage. They also may be attractive from a packaging standpoint. Unfortunately, the bulkiness and weight of radial inflow turbines place them at a disadvantage in aircraft propulsion systems. To address this issue, a joint program was established between Pratt and Whitney Aircraft and NASA Lewis Research Center to significantly reduce the axial length, and thereby weight, of a radial-in-flow turbine rotor.

This paper is declared a work of the U.S. Government and is not subject to copyright protection in the United States.
Under a Cooperative Endeavor Agreement, Pratt and Whitney designed two highly loaded compact radialin-flow turbine rotors. Both parties analyzed the rotor flow fields with their respective design systems, and NASA Lewis conducted aerodynamic performance tests.

The program goal was to reduce the rotor axial length by $40-50$ percent and the weight by 20-30 percent while achieving equal or higher efficiency compared to conventional state-of-the-art radial rotors. The reduction in axial length was accomplished primarily by shortening the exducer portion of the blade, which normally has the lowest aerodynamic loading. Carefully controlling the flow to avoid high losses in such a significantly shorter blade was made possible with the use of modern three- dimensional flow analysis codes. A nozzle and two rotors were designed to turbine requirements suitable for a main propulsion engine in rotorcraft and/or regional commuter aircraft. The design approach and performance results for the compact rotor turbines are reported in reference 1 . The experimental performance tests conducted in the Lewis Warm Turbine Facility ${ }^{(2)}$ verified stage efficiencies equal or better than conventional rotors for this compact rotor concept.

To further understand the aerodynamic characteristics of the compact rotor concept, a fully threedimensional (3-D) viscous analysis and a quasi 3-D inviscid/boundary layer analysis were made at the Lewis Research Center. The two analytical studies utilized entirely different computer codes and have different purposes. The viscous analysis code is a fully 3-D "average passage" formulation that calculates the entire blade passage flow field and is used to analyze statorrotor interaction effects of one or more stages. The results of that analysis for the compact radial turbine are reported in reference 3 . The quasi-3D analysis system, which is the subject of this paper, is a rapid running blade design and loss analysis tool. It calculates 
the inviscid flow field, the surface boundary layer and the blade losses, using empirical correlations, for a single blade row. The system of computer codes used for the inviscid analysis is referred to as MTSB and is described in reference 4. Additional details of MTSB and the analysis methodology are given in the Analysis Procedure.

The analysis of the compact turbine with MTSB was conducted to identify and quantify the loss sources, determine the differences between the three configurations and indicate possible areas of performance improvement. In addition, comparison of the calculated stage performance with measurements were used to evaluate the MTSB loss system for radial turbines. The loss correlations in MTSB are heavily based on axial turbine data and predict the performance of those turbines very well, reference 4 . The application of this procedure to the design of a highly contoured radial turbine is described in reference 5. However, test data were not available to assess the prediction's accuracy. The comparison of the MTSB performance prediction results with experimental data for a conventional radial turbine is discussed in reference 6 .

This report describes the application and results of the quasi- three dimensional analysis of the three compact radial turbines tested. The calculated loss constituents are tabulated and overall performance compared to the experimental results. Comparison of the analysis with experimental data is made at the design speed, weight flow, and pressure ratio. In addition, MTSB was used to calculate the off-design losses at design speed for one turbine configuration and the results compared to test values. Stator and rotor blade surface static pressures were also calculated and compared for the inviscid and viscous analyses. Finally, improvements to the MTSB loss models applicable to radial turbines are discussed.

\section{TURBINE DESCRIPTION}

Figure 1a shows the two compact radial turbine rotors along with a conventional rotor. The compact turbines are approximately 42 and 52 percent shorter in axial length compared to the conventional rotor. Each rotor had 14 blades. The backface of the rotor is scalloped, i.e., the backface disk does not extend all teh way to the leading edge of the blade for weight and stress considerations. With a scalloped hub flow leakage can occur in the backface region as well as in the blade tip shroud region. The stator, which had 36 vanes, is shown in figure $1 \mathrm{~b}$. The flow enters radially through the inlet vanes and is turned tangentially approximately 67 degrees with the design stator.

Three turbine stage configurations were evaluated in the experiment and analyzed with MTSB. They are: (1) Rotor I with the design inlet vanes; (2) Rotor I with the stator vanes closed down 1.125 degrees; (3), Rotor II with the closed down vanes. The three configurations are referred to in the text as Rotor I Stator I, Rotor I Stator II, and Rotor II Stator II, respectively. Rotor II was designed to be physically smaller than rotor I and therefore had a lower blade speed for the same rotative speed. However, both rotors were scaled up to a tip diameter of .367 meters (14.59 inches) for the experimental evaluation and the rpm of rotor II decreased to match the design equivalent conditions. The test conditions for the three configurations are given in table I. Additional design information is contained in reference 1.

\section{ANALYSIS PROCEDURE}

The analysis used the quasi-3D procedure developed for axial turbines by Boyle, Haas, and Katsanis ${ }^{(4)}$. The quasi-3D flow analysis was done by first obtaining a hub-to-shroud midchannel flow solution using a modified version for the MERIDL code developed by Katsanis and $\mathrm{McNally}(7)$. The results were then used to obtain a series of blade-to-blade solutions using the TSONIC code developed by Katsanis ( 8 ). The flow solutions were then used as input to a modified version for the BLAYER boundary layer analysis of $\mathrm{McNally}^{(9)}$. The results of the boundary layer analyses were used along with correlations for incidence, tip clearance and secondary flow loss to obtain the predicted efficiency of the stage.

Civinskas and Povinelli ${ }^{(5)}$ made additions to the procedure to extend the analysis to radial turbines. They added Wiesner's ${ }^{(10)}$ optimum incidence model, and used the radial turbine clearance model of Futral and Holeski $i^{(11)}$ to predict efficiencies in a radial turbine designed to avoid separation.

The clearance model used by Civinskas and Povinelli did not account for any additional loss due to a backface scallop. A radial clearance loss model, similar to the one proposed by Rodgers ${ }^{(12)}$, was used herein in the efficiency predictions. In this clearance loss model the change in stage efficiency, $\Delta \eta_{\mathrm{CL}}$, as a fraction of the zero clearance efficiency, $\eta_{0}$, is given as a function of three rotor clearances. This model is:

$$
\frac{\Delta \eta_{\mathrm{CL}}}{\eta_{0}}=L_{a} C_{a}+L_{r} C_{r}+L_{b} C_{b}
$$

$C_{a}$ is the axial clearance, $C_{r}$ is the radial clearance, and $C_{b}$ is the backface clearance. Both $C_{a}$ and $C_{b}$ are 
found by dividing the actual axial and backface clearances by the inlet span. $C_{r}$ is the ratio of the radial clearance to the span at the exit. The coefficients $L_{a}$ and $L_{r}$ were given as 0.15 and 1.6 respectively by Futral and Holeski(11) for a radial turbine with no scallop. Rogers ${ }^{(12)}$ stated that the equivalent shroud axial clearance equals the front shroud plus one half the back shroud clearance. This approach, if used in the present designs, would result in a very small efficiency penalty due to the presence of the scallop. The efficiency loss due to the scallop would be less than $15 \%$ of the total efficiency loss due to clearance. The coefficient $L_{b}$ was instead taken as 0.8 , resulting in the efficiency loss due to the scallop clearance being nearly $60 \%$ of the total clearance loss. In axial turbines the clearance loss is often taken as a function of rotor tip reaction (Glassman $^{(13)}$ ). No information was found in the open literature regarding the effect of tip loading on rotor clearance loss for radial turbines, and so none was used in the present analysis.

Secondary loss correlations such as Morris and Hoare $^{(14)}$, and Dunham ${ }^{(15)}$ account for both the loss due to an inlet boundary layer and the loss due to endwall boundary layer. The analysis used herein explicitly accounts for the endwall boundary layer loss, and uses a correlation only for the loss due to the inlet boundary layer. The loss correlation used is the same as that used in reference 4 , and is:

$$
Y_{\mathrm{SEC}}=0.44 Z \frac{\cos \alpha_{2}}{\cos \beta_{1}}\left(\frac{c}{h}\right)\left(\frac{\delta_{1}}{c}\right)
$$

As observed by Civinskas and Povinelli( ${ }^{(5)}$ one for the deficiencies of the analysis procedure of reference 4 is the treatment of separated flow. In this procedure, when the predicted velocity distribution resulted in separation, the velocity distribution was smoothed sufficiently so that no separation occurred. Losses were calculated using the boundary layer parameters calculated using the smoothed velocities. This resulted in higher predicted losses for cases without separation than for cases with massive separation. To remedy this situation the boundary layer analysis procedure was modified. For the analysis used herein, whenever separation occurred, the boundary layer parameters were held constant from a point just upstream of separation to a location where a favorable pressure gradient indicated no separation. The parameters which were held constant in the separated region were the boundary layer thicknesses and form factors.

The MTSB performance prediction analysis is performed using experimentally measured values of tem- perature, pressure, rotative speed, and massflow as input. To obtain the MTSB stage solution the blade rows are run sequentially. The stator performance and exit swirl are first determined. For transonic flows a check is made to insure that the ratio of the stator exit static pressure to the inlet total pressure is consistent with the experimental value. The stator exit conditions are then used as input to the rotor analysis. If the calculated stage total pressure ratio differs from the experimental one, conditions are modified until the desired pressure ratio is achieved. The primary convergence criteria for each blade row is that the trailing edge Kutta condition is satisfied along the entire span. Losses affect the flow solution for each blade row, and are updated during the iteration for the blade row exit swirl.

\section{RESULTS}

Figure 2 shows the computational mesh used for analyzing Rotor I Stator I hub-to-shroud flow. Similar meshes were used to analyze the other two stages.

\section{SURFACE VELOCITIES}

Blade surface velocities are shown in figures 3 through 5 depicting Rotor I Stator I, Rotor I Stator II, and Rotor II Stator II configurations respectively. The velocities shown are at the hub, mean and tip regions of each blade.

Stator I accelerates the flow to a maximum value of velocity $\mathrm{V} / \mathrm{Vcr}=1.2$ at approximately 70 percent of the blade meridional distance. The maximum velocities occur at the hub and tip regions. Stator II has a maximum velocity ratio of 1.3 due to the closed down nature of the flow. For both rotors the stator velocities are similar with Rotor II resulting in a slightly higher peak stator velocity ratio.

The rotor surface velocities show that after the flow accelerates at the leading edge of the blade, diffusion takes place. The inlet velocities are higher for Rotor II than for Rotor I. However, the highest surface velocity occurs on Rotor I at the tip of the blade in the exducer region. Analysis showed small areas of separation in the rotors for all three configurations. Rotor I Stator I showed a separation region starting at approximately $37 \%$ of the meridional distance. Due to the favorable pressure gradients farther downstream, the analysis predicted reattachment at approximately $42 \%$ of the meridional distance. The Rotor I Stator II configuration showed a similar separation region near the hub. For this configuration the flow also separated in the tip region near the trailing edge. Rotor II had hub region separation between $50 \%$ to $55 \%$ of the meridional distance, and no separation in the tip region. 


\section{BLADE STATIC PRESSURES}

Figures 6 through 8 show the blade loading computed for the three configurations. Surface static pressure contours are shown normalized with inlet total pressure, $(P / 0)$. The stator blades shown have minimum static-to-total pressure ratios between .35 and .45 , The minimum static pressure occurs on the suction surface at approximately 70 percent of the chord. High adverse pressure gradients occur at the exit of the stator on the suction side of the vanes.

The static pressure distributions are determined from the inviscid velocity distributions. Because the total pressure is nearly constant, the pressures streamwise are nearly the same as those calculated from the isentropic relations.

In contrast with stators, the rotor has a varying relative total pressure change due to the change in radius with meridional distance. The rotor pressure contours on the suction side show that the flow at the inlet has high pressure gradients. These gradients are due to the change in relative total pressure, as well as the decreasing static pressure with the radius. Comparing the suction and pressure surface pressure distributions shows that the rotor blades have highest loading in the shroud region. The suction side of Rotor II contours show low pressure areas near the inducer. These areas are located near the back face of the rotor where the blade is scalloped. The low pressure shown in the Rotor II inducer backface area is unique to Rotor II. All rotor configurations show a low pressure area at the tip region in the bend of the blade. These regions of low pressure on the suction side of the blade can result in large leakage of flow from the pressure side.

A comparison was made between the calculated MTSB surface static pressures made and those calculated by Heidmann ${ }^{(3)}$ using a viscous fully $3-\mathrm{D}$ "average passage" code. The stator comparisons are shown in figure 9 , and the rotor comparisons are shown in figure 10. The comparison was made for the Rotor I Stator I configuration. These figure shows three streamlines near the hub, at midspan, and near the tip. Figure 9 shows that the fully $3 \mathrm{D}$ viscous solution predicts the stator minimum suction side pressure to occur further downstream than the MTSB analysis. However, both analyses show nearly the same minimum pressure level at each streamline. Figure 10 shows similar behavior for the rotor. The differences may be due to differences in the loss distribution. An empirical distribution of losses was used in the MTSB analysis. The fully 3D viscous analysis accounted for all clearances. While the MTSB analysis predicted separation for this rotor configura- tion, the fully $3 \mathrm{D}$ solution did not. A slight variation in exit pressures used to run the two cases caused the difference in the loading at the trailing edges of both stator and rotor. Overall the agreement with the two calculations is reasonable.

\section{LOSSES}

Figure 11 compares the predicted and experimental loss for the three configurations at design conditions. Also shown is a breakdown of the predicted loss. The first two configurations have nearly the same test efficiency. Configuration three had about a one-half point lower efficiency. The analysis predicted a variation of less 0.6 points in efficiency among the three configurations. The analysis underpredicts the experimental loss by less than 1.7 points. This was similar to the results of reference 4 where the analysis predicted the design point efficiency within 1.2 points for nine axial turbine stages.

The loss breakdown shows that clearance loss is the major predicted loss mechanism. As discussed previously, the clearance loss model adopted was expected to be conservative with respect to the loss prediction. It was felt that the model was more likely to overpredict the loss due to clearance, than to underpredict this loss. However, the data show higher losses than predicted. This indicates that if the clearance loss model is conservative, it is not unduly conservative.

The stator loss is the next largest loss component at the design. This loss is the sum of profile, endwall, and secondary flow losses. Approximately $43 \%$ of the stator loss was profile loss. The endwall loss, which accounted for boundary layer growth up to the rotor leading edge was $50 \%$ of the total loss. The remainder is due to secondary loss, which is small because of the large span at the stator inlet.

The rotor profile loss is also a significant loss. The profile loss is calculated from the trailing edge blockage and boundary layer growth. It is not expected to be a major source of uncertainty in the loss calculation. The endwall and secondary loss together are smaller than the predicted rotor profile loss. The rotor endwall loss is small because the exit span is large relative to the hub endwall momentum thickness. The rotor secondary loss is small because of the acceleration in the vaneless space. While the endwall and secondary losses have higher uncertainties than the profile loss, their uncertainties are not sufficient to account for the differences between the measures and predicted stage losses.

It is somewhat surprising to see a significant inci- 
dence loss at the design point. The reason for relatively high loss at design is that the incidence loss model predicts that the optimum incidence angle occurs when the ratio of absolute tangential velocity to wheel speed, $\left(V_{u} / U\right)$, is less than 1 . Other incidence loss models for radial turbines also have this characteristic. However, at the design point $V_{u} / U$ was predicted to be greater than 1 . This was true for all three configurations. The measured values of the stator pressure ratio confirmed this. Figure 12 shows the predicted and measured efficiency as a function of overall pressure ratio at the design speed for the Rotor II Stator II configuration. The comparisons were similar for all three configurations. As the stage pressure ratio decreased, the stator pressure ratio decreased. Consequently, $V_{u} / U$ decreased, and the predicted incidence loss decreased. This resulted in increased predicted efficiency at lower pressure ratios. The experimental efficiency remained fairly constant over the range of pressure ratios. These results indicate a deficiency in the incidence loss model. A partial explanation for the inaccuracy of the incidence model might be the use of elliptical leading edge for both the stator and rotor blades. All of the incidence loss models are based on circular leading edges.

\section{SUMMARY AND CONCLUSIONS}

Three compact radial turbines were analyzed using MTSB, a quasi- 3D inviscid and boundary layer analysis. The results of the analysis were compared with experimental data. At design conditions MTSB predicted the test efficiencies within 1.7 points for all three configurations. The calculated loss sources suggest that designs, such as these tested, which have optimum efficiencies at high values of $V_{u} / U$, can result in efficiency gains of up to two points due to minimization of the incidence loss.

Comparisons of blade surface static pressures calculated using MTSB agreed reasonably well with those calculated using a fully three-dimensional viscous code. However, MTSB predicted some small regions of separation in the rotors, which were not predicted using the viscous analysis. The turbine test program did not provide information to confirm either flow situation.

The use of MTSB to predict the off design performance of these compact radial turbines was not entirely successful. As the stage pressure ratio was decreased along a constant design speed line, MTSB predicted an increase in efficiency. However, the experimental data show nearly constant efficiencies over the same range of pressure ratios. The cause of this discrepency was the incidence model being used. This discrepency indi- cates the need for an improved incidence model. The clearance loss model used for the radial turbine performance calculation gave reasonable results. The importance of the clearance loss to the overall loss shows the importance of an accurate clearance loss model. A precise model would include more factors than were used in the simplified clearance model used in this analysis. Overall the changes made to MTSB to extend its use to radial turbines has enhanced its usefulness in analyzing the advanced compact radial turbines.

\section{ACKNOWLEDGEMENTS}

Funding for this work was provided under NASA contract NAS3-25266. Thanks are extended to Mr. Richard Roelke of NASA Lewis Research Center for his many hours of technical advice.

\section{REFERENCES}

1. A.J. Friedmonski and F. Huber, P.S. Simonyi, R.J. Roelke, "Design and Experimental Evaluation of a Compact Radial-Inflow Turbine," AIAA paper 912127, June, 1991.

2. Nowlin, B.C., Verhoff, V.G., "Small Engine Components Test Facility Turbine Testing Cell, " AIAA-88-1963, July, 1988.

3. Heidmann, J.D., "A Three Dimensional NavierStokes Stage Analysis of the Flow Through a Compact Radial Turbine", AIAA paper 91-2134, June, 1991.

4. Boyle, R.J., Haas, J.E., and Katsanis, T., "Comparison Between Measured Turbine Stage Performance and the Predicted Performance Using Quasi-3D Flow and Boundary Layer Analyses," NASA TM-83640, 1984

5. Civinskas, K.C., Povinelli, L.A., "Application of a Quasi-3D Inviscid Flow and Boundary Layer Analysis to the Hub-Shroud Contouring of a Radial Turbine," AIAA paper 84-1297, 1984.

6. Tirres, L., "A Comparison of the Analytical and Experimental Performance of the Solid Version of a Cooled Radial Turbine," AIAA-91-2133, June, 1991.

7. Katsanis, T., McNally, W.D., "Revised FORTRAN Program for Calculating Velocities and Streamlines on The Hub-Shroud Midchannel Stream Surface of an Axial-, Radial-, or Mixed- Flow Turbomachine or Annular Duct, I-User's Manual," NASA TN D-8430, 1977.

8. Katsanis, T., "FORTRAN Program for Calculating Transonic Velocities on a Blade-to-Blade Stream Surface of a Turbomachine," NASA TN D-5427, 1969. 
9. McNally, W.D., "FORTRAN Program for Calculating Compressible Laminar and Turbulent Boundary Layers in Arbitrary Pressure Gradients," NASA TN D-5681, 1970.

10. Wiesner, F.J., "A Review of Slip Factors for Centrifugal Impellers," Journal of Engineering for Power, Vol. 89 Oct. 1967, pp. 558-572.

11. Futral, S.M.,Jr., Holeski, D.E., "Experimental Results of Varying the Blade Shroud Clearance in a 6.02 Inch Radial Inflow Turbine," NASA TN D$5513,1970$.

12. Rogers, C., "Review of Mixed Flow and Radial Turbine Options" AIAA paper 90-2414, July, 1990.

13. Glassman, A.J.; ed.: "Turbine Design and Application," NASA SP-290 Vol-1, 1973.

14. Morris, A.W.H., Hoare, R.G., "Secondary Loss Measurements in a Cascade of Turbine Blades with Meridional Wall Profiling," ASME Paper 75WA/GT-13, Nov. 1975.

15. Dunham, J., "A Review of Cascade Data on Secondary Losses in Turbines," Journal of Mechanical Engineering Science, Vol. 12, Feb. 1970, pp 48-59.

\begin{tabular}{|l|r|r|c|}
\hline & Rotor I Stator I & Rotor I Stator II & Rotor II Stator II \\
\hline TO, R & 860.000 & 860.000 & 860.000 \\
\hline P'O, psia & 48.400 & 48.400 & 45.500 \\
\hline Spec. Work, Btu/lbm. & 69.400 & 66.030 & 67.870 \\
\hline Work Factor & 1.091 & 1.048 & 1.195 \\
\hline D tip, in. & 14.459 & 14.459 & 14.459 \\
\hline Rotor Tip Speed, f/s & $1,263.200$ & 1.257 .300 & 1.194 .000 \\
\hline Rotative Speed, RPM & $20,022.500$ & 19.928 .500 & 18.926 .400 \\
\hline Mass Flow Rate, Ib/s & 6.295 & 5.940 & 5.630 \\
\hline Power, HP & 617.970 & 554.780 & 540.510 \\
\hline P'in/P'out & 5.000 & 5.000 & 5.000 \\
\hline
\end{tabular}

Table I.- Turbine test conditions 


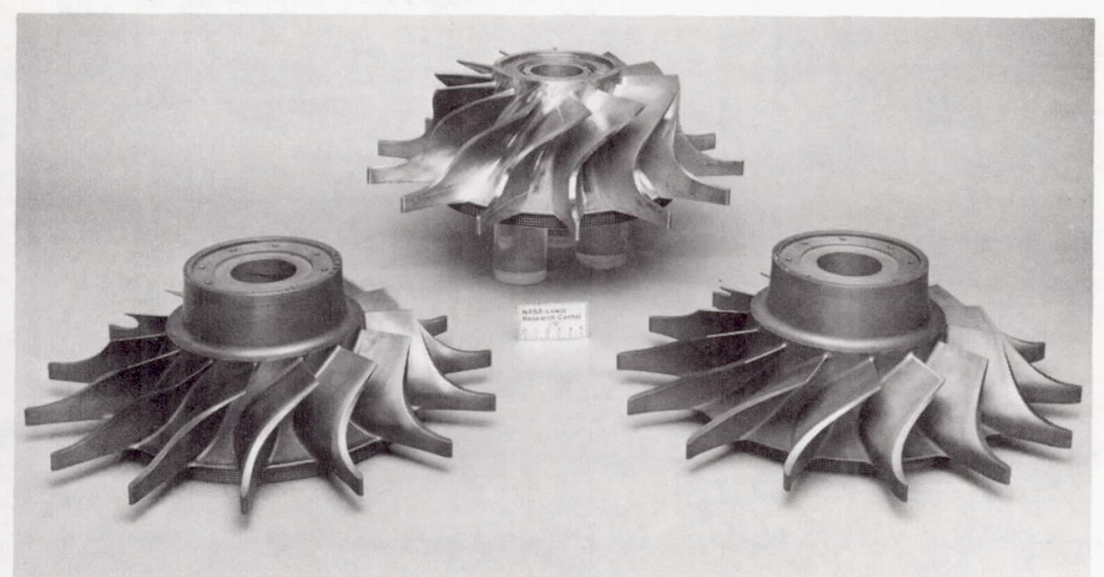

Figure 1a.- Compact and conventional size turbine rotors

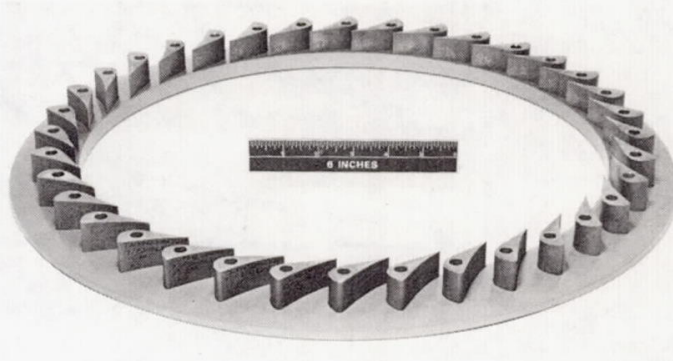

Figure 1b.- Stator vanes

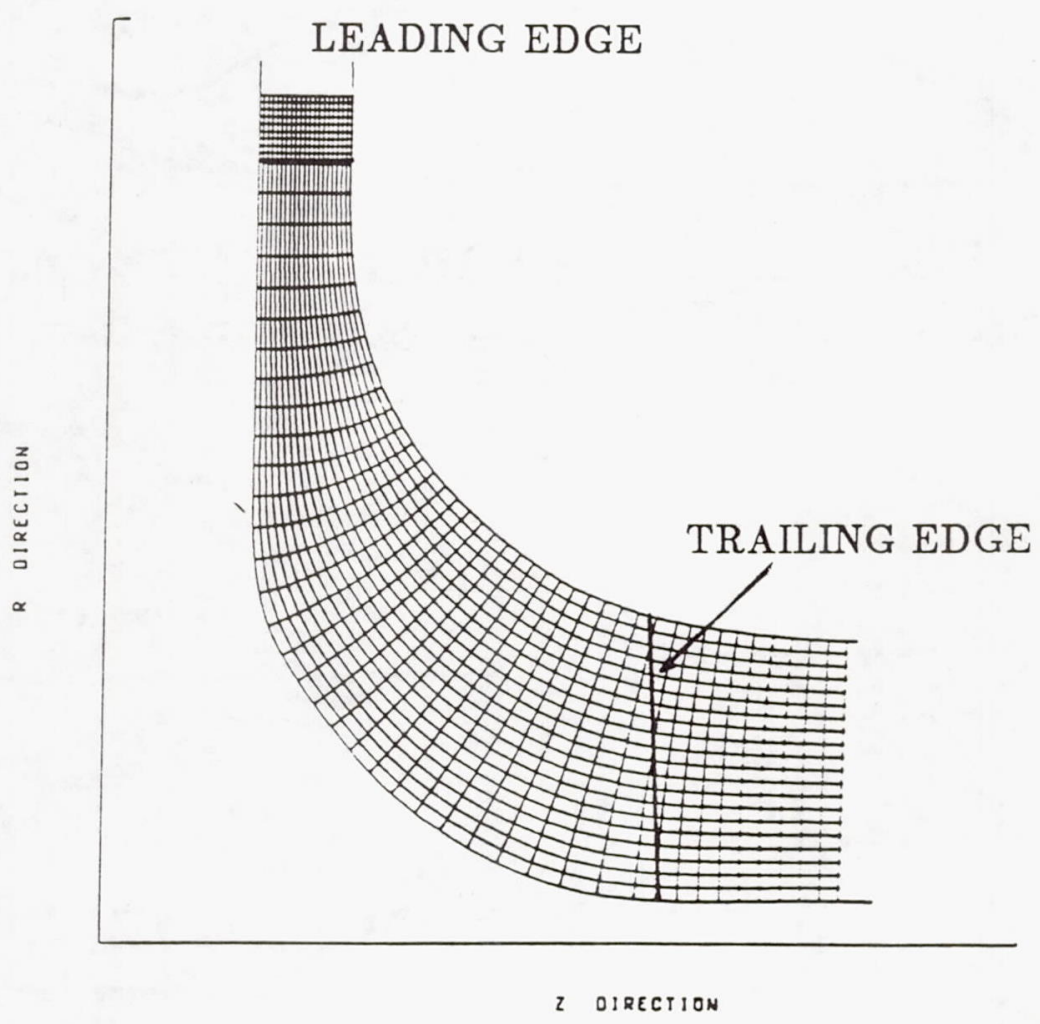

Figure 2.- MTSB computational mesh 
Stator Surface Velocities

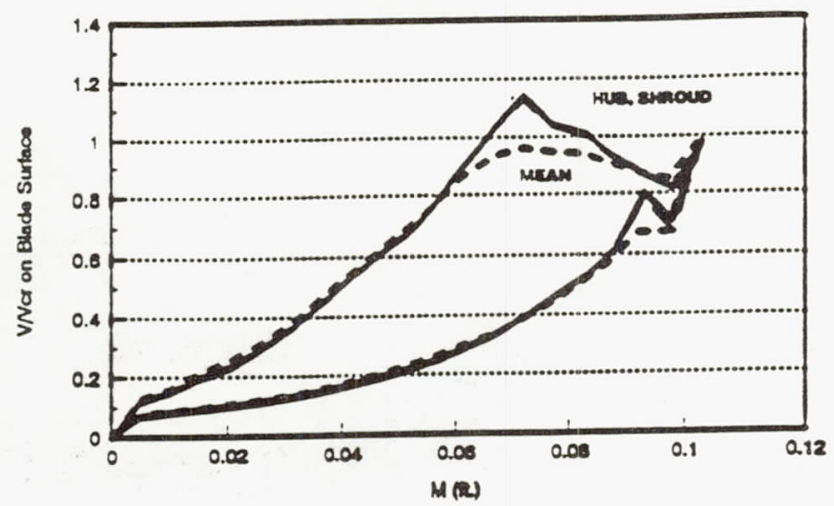

Rotor Surface Velocities

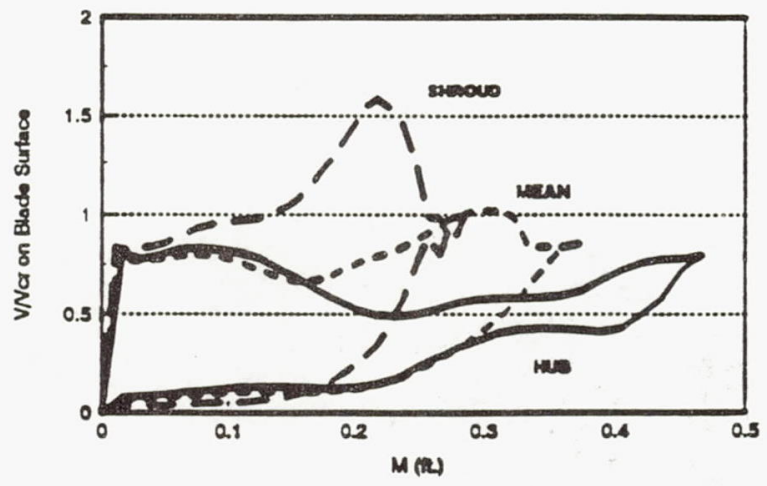

Figure 3.- Rotor I Stator I calculated blade surface velocities
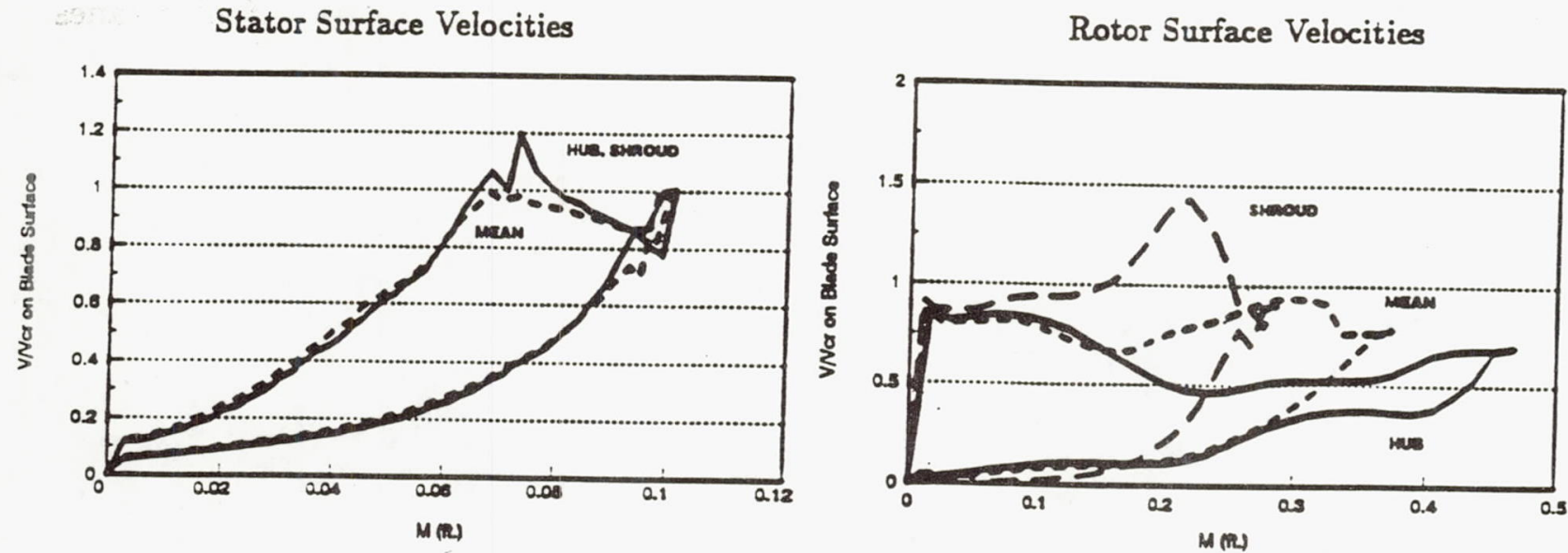

Figure 4.- Rotor I Stator II calculated blade surface velocities

Stator Surface Velocities

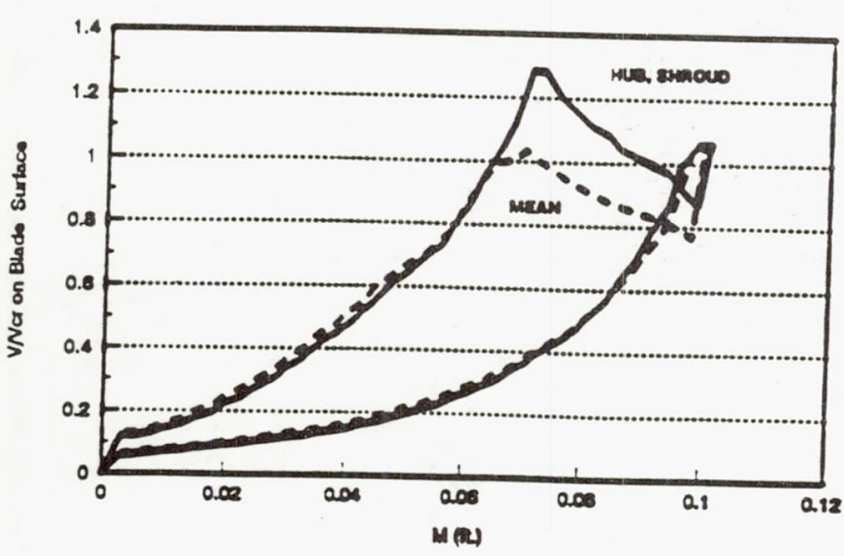

Rotor Surface Velocities

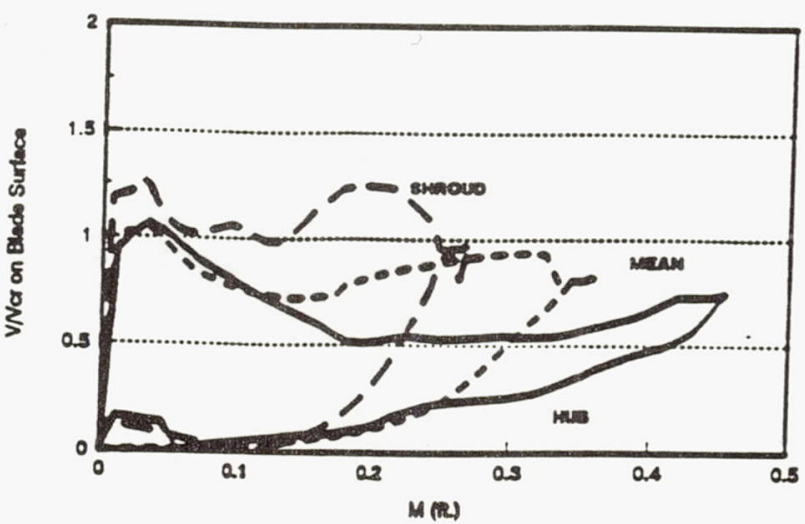

Figure 5.- Rotor II Stator II calculated blade surface velocities 


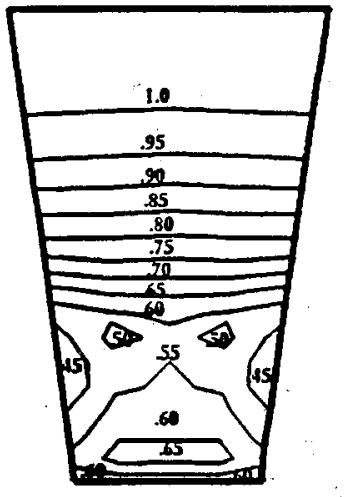

STATOR SUCTION SIDE

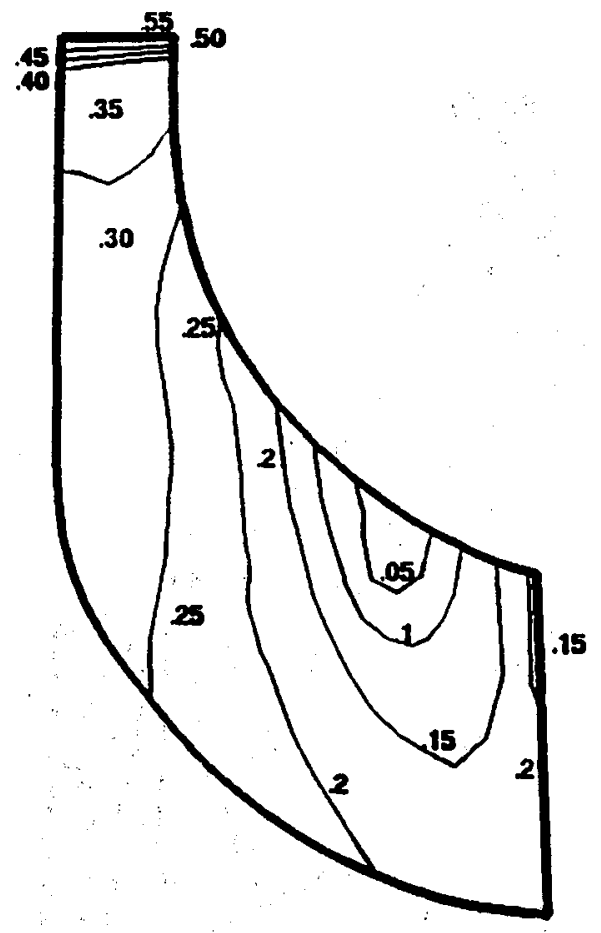

ROTOR SUCTION SIDE

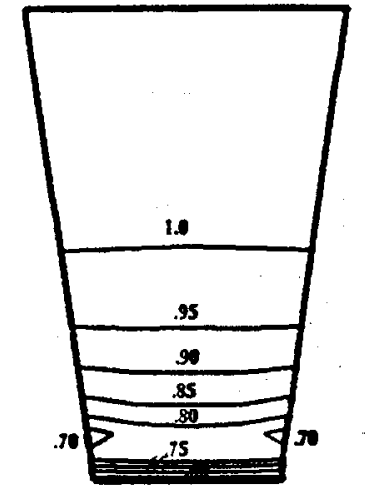

STATOR PRESSURE SIDE

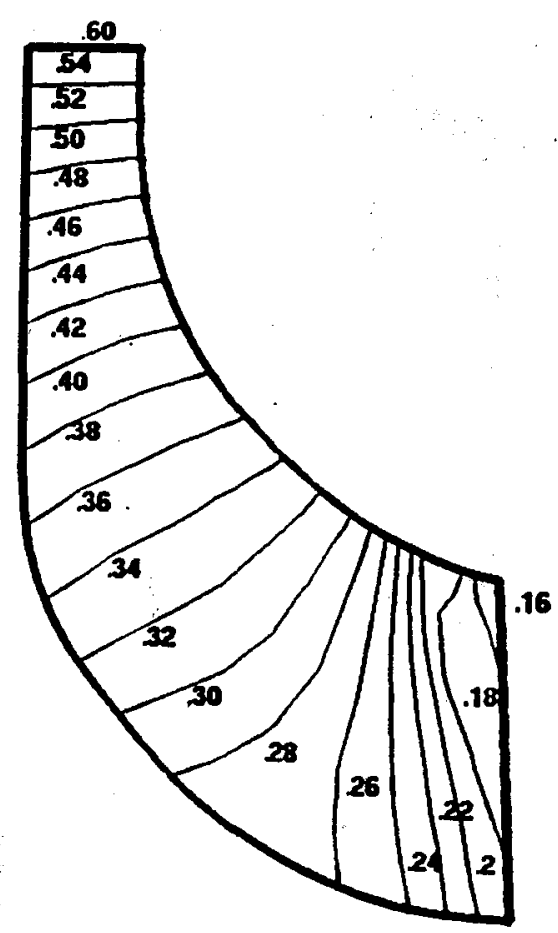

ROTOR PRESSURE SIDE

Figure 6.- Calculated blade loading, surface static pressure contours for Rotor I Stator I 


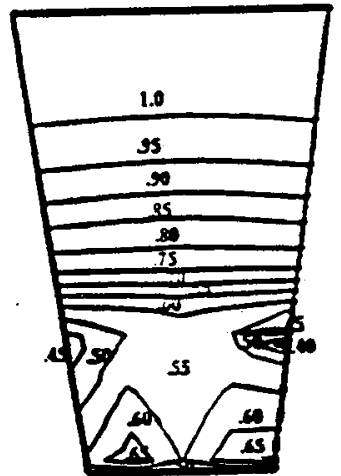

STATOR SUCTION SIDE

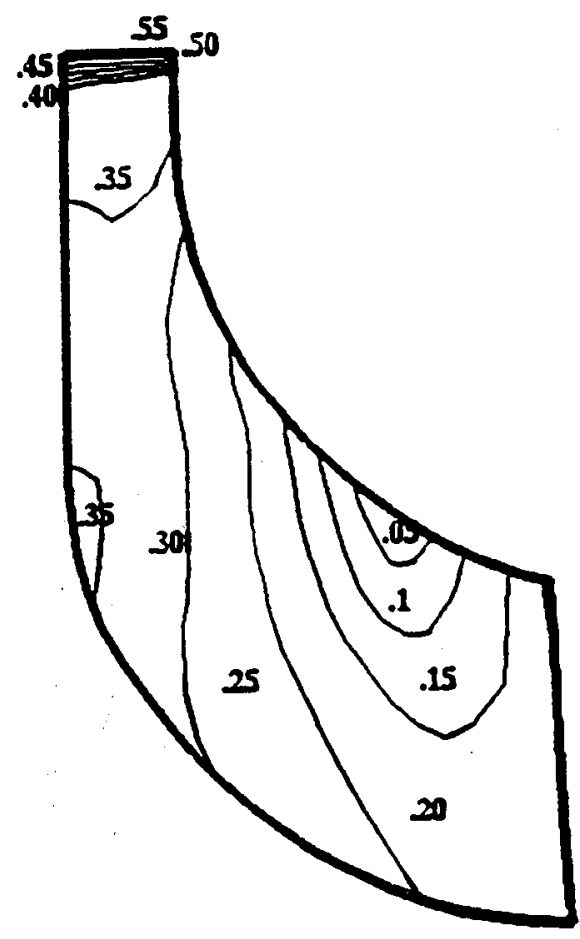

ROTOR SUCTION SIDE

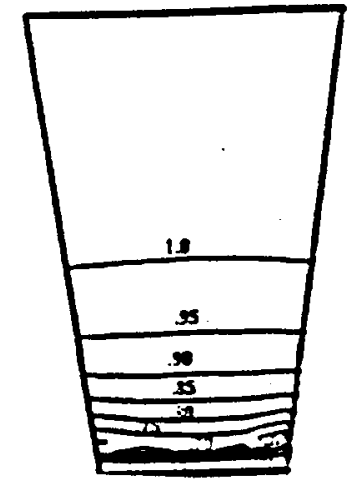

STATOR PRESSURE SIDE

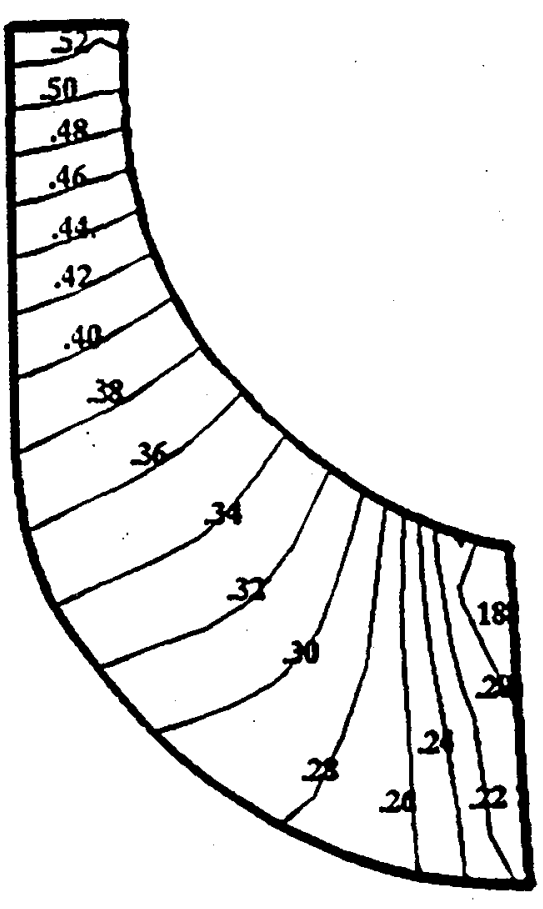

ROTOR PRESSURE SIDE

Figure 7.- Calculated blade loading, surface static pressure contours for Rotor I Stator II 


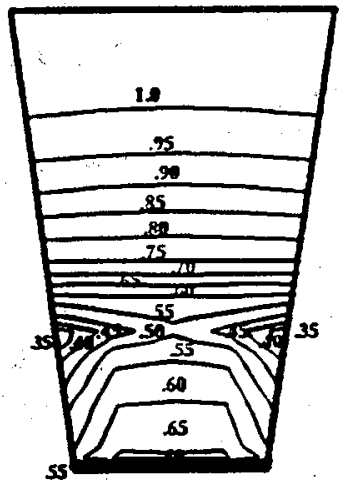

STATOR SUCTION SIDE

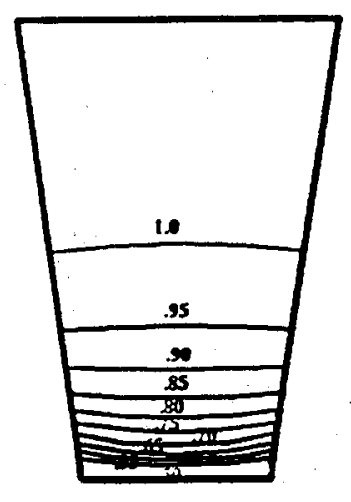

STATOR PRESSURE SIDE

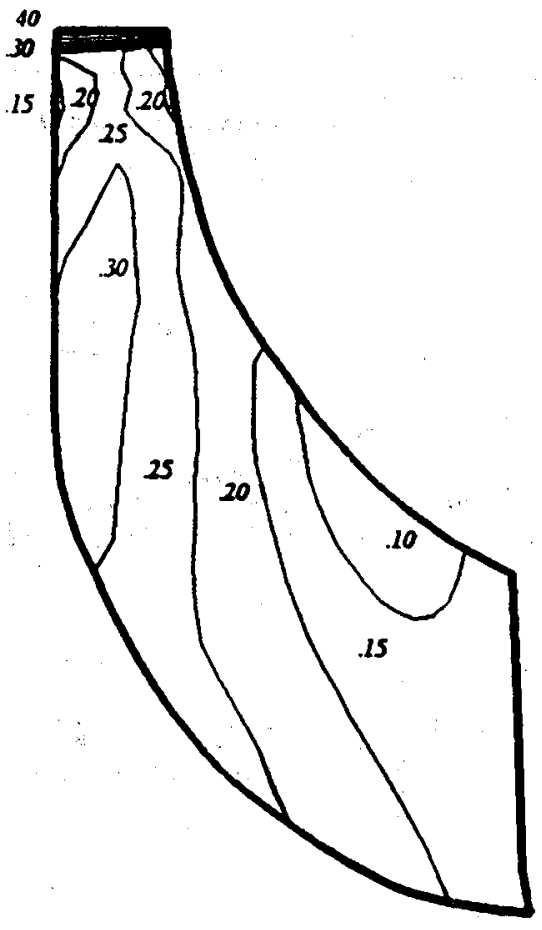

ROTOR SUCTION SIDE

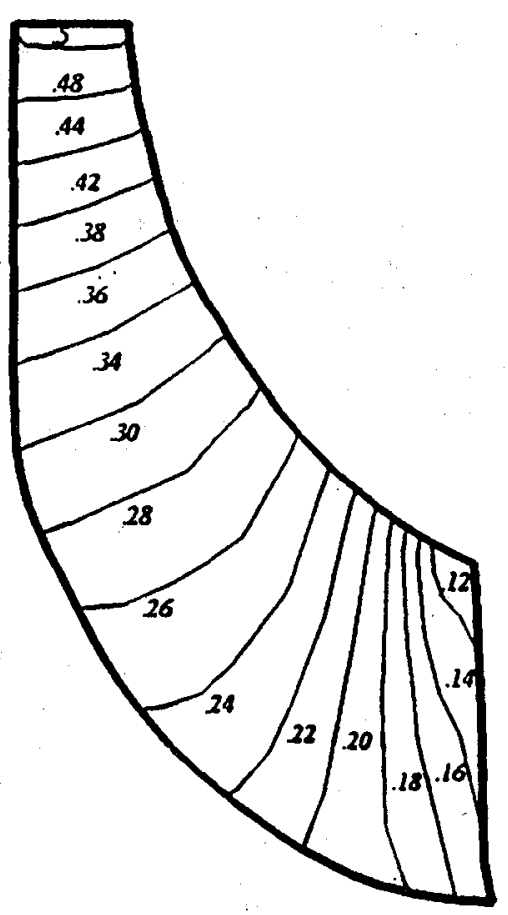

ROTOR PRESSURE SIDE

Figure 8.- Calculated blade loading, surface static pressure contours for Rotor II Stator II 

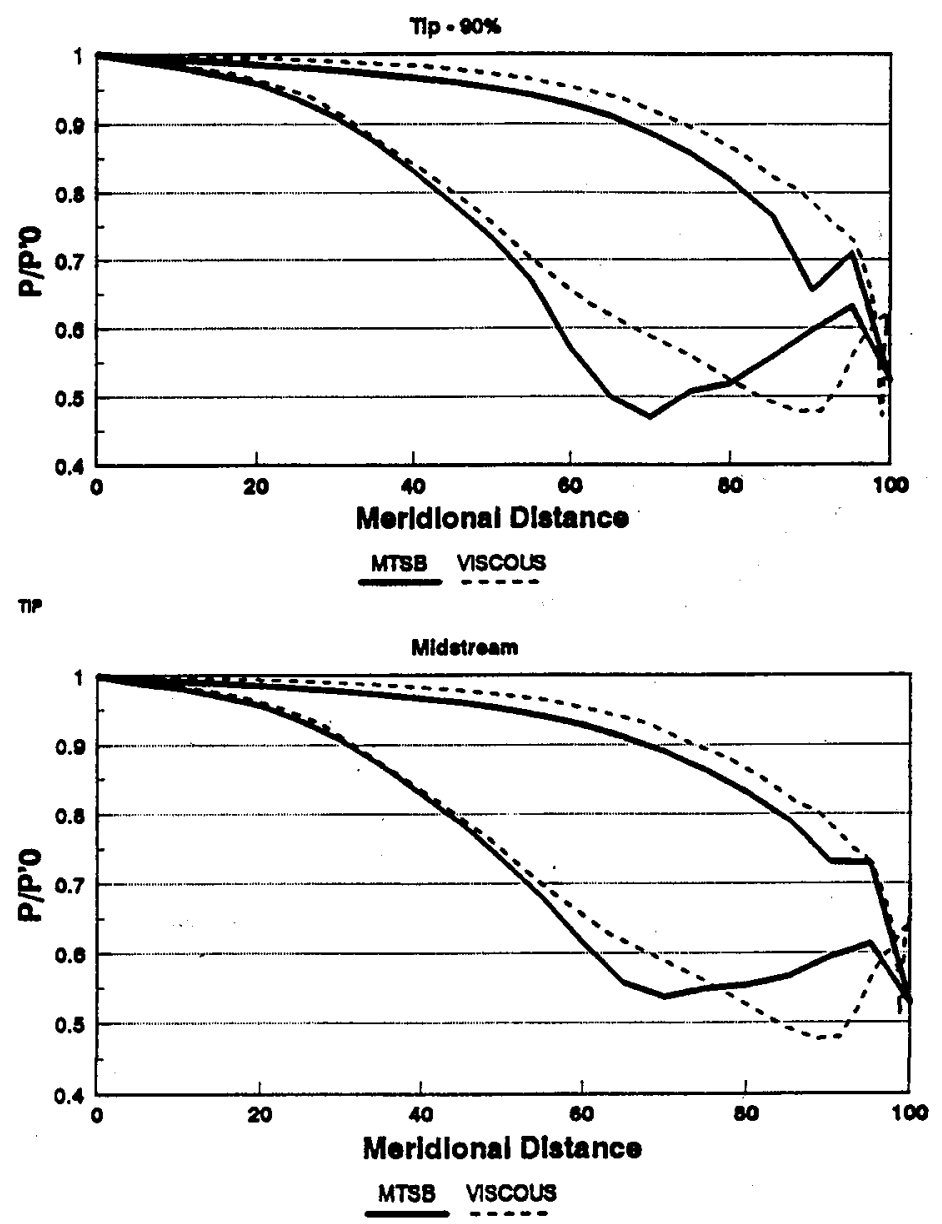

WD

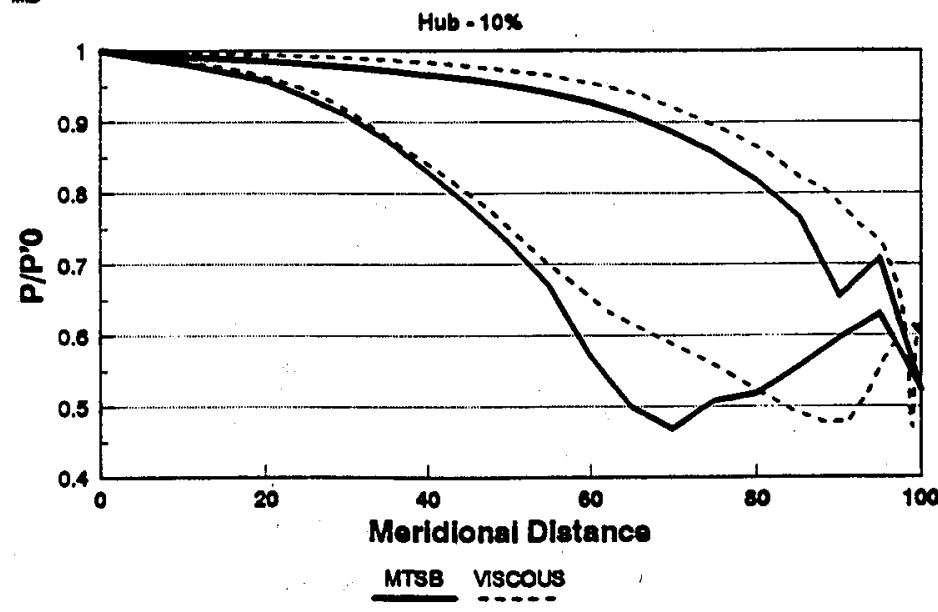

Figure 9.- Stator surface static pressures for MTSB and viscous $3 \mathrm{D}$ predictions, Rotor I Stator I.
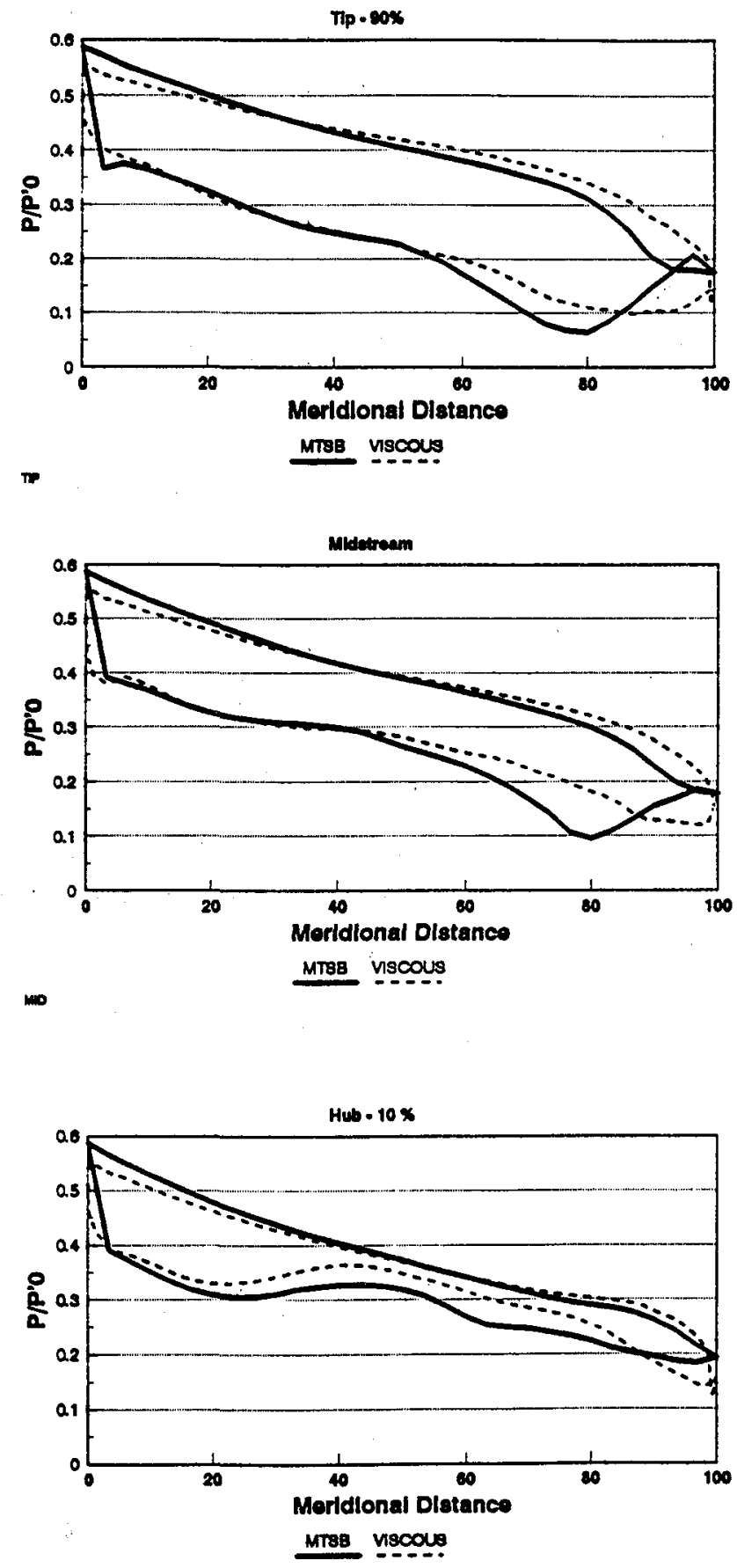

Figure 10.- Rotor surface static pressures for MTSB and viscous $3 \mathrm{D}$ predictions, Rotor I Stator I 


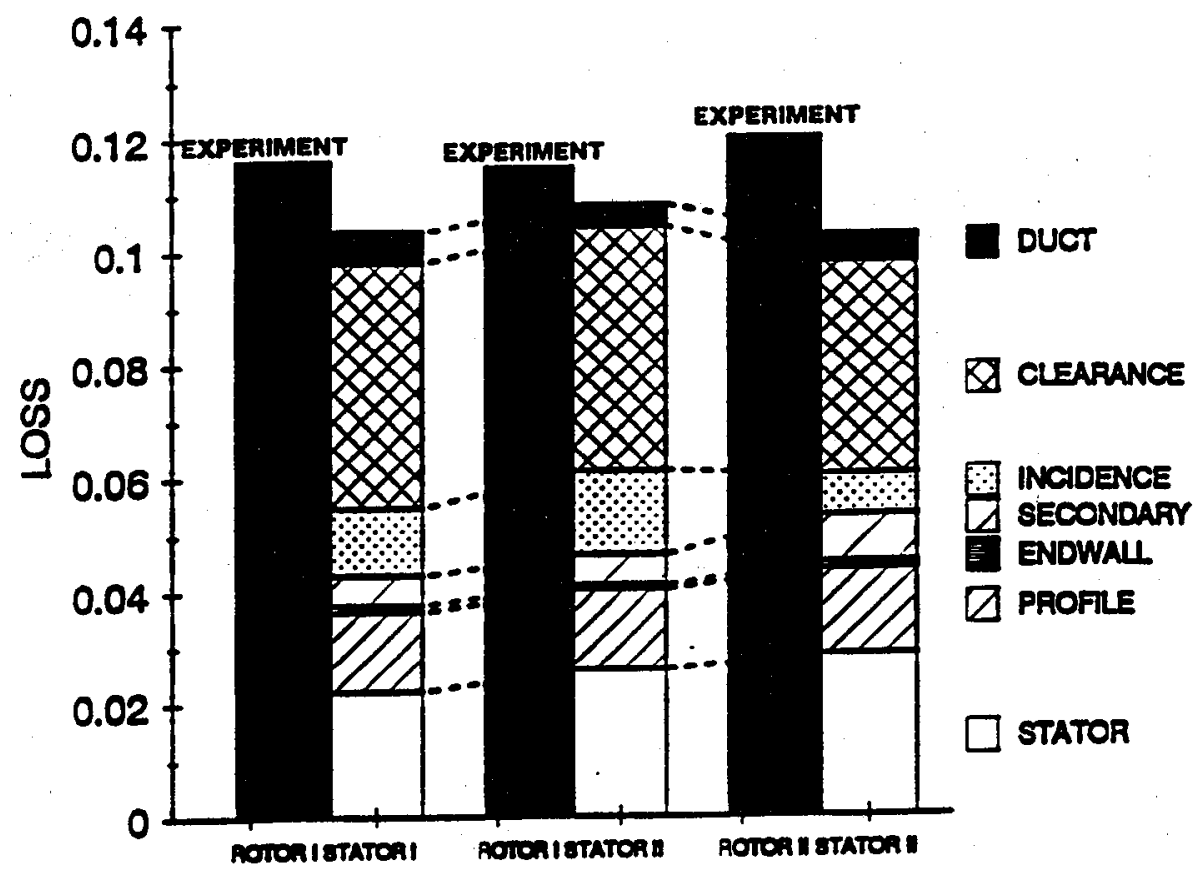

Figure 11.- Comparison of experimental and computed losses for the three turbine stages

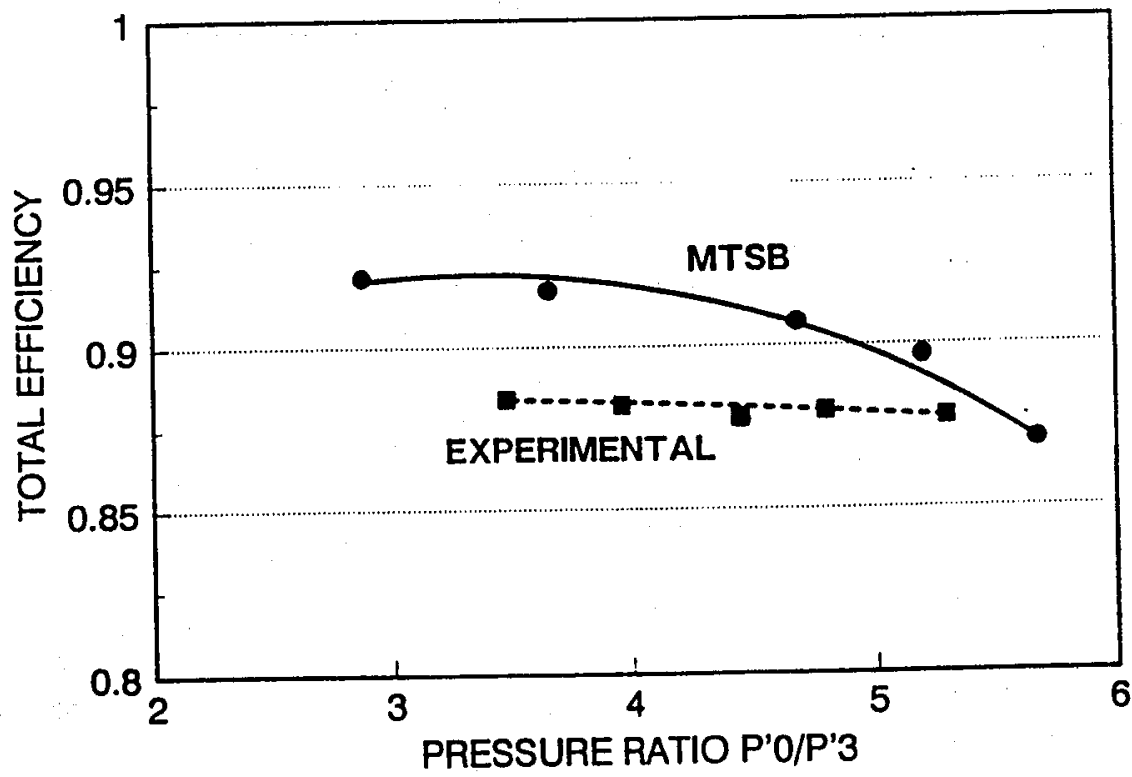

Figure 12.- Predicted and measured efficiencies for Rotor II Stator II 


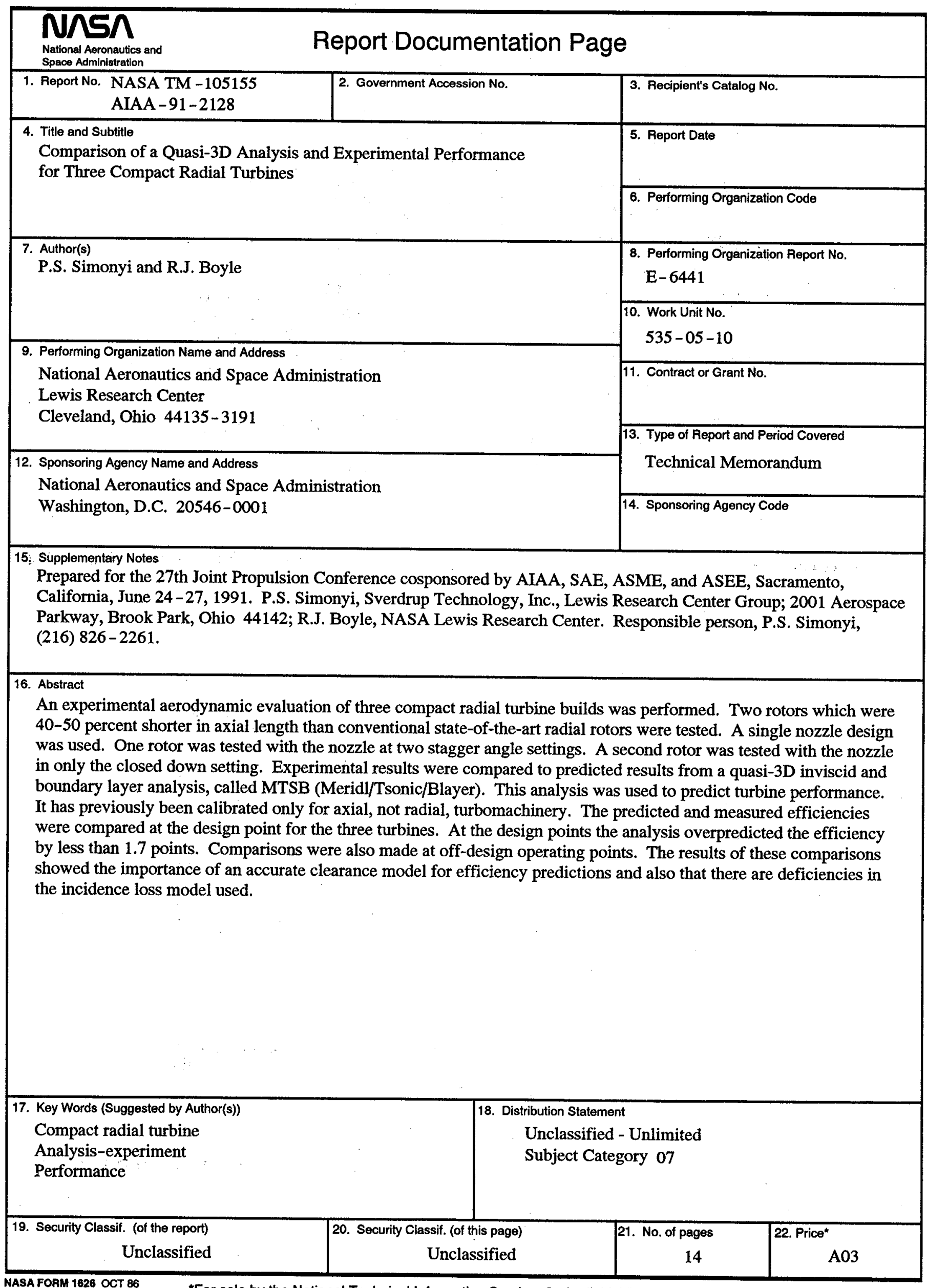


National Aeronautics and

Space Administration

Lewis Research Center

Cleveland, Ohio 44135

Official Business

Penalty for Private Use $\$ 300$

Postage and Fees Paid National Aeronautics and

Space Administration NASA 451 